\title{
The use of ex-vivo liver perfusion circuit in sheep model
}

\author{
Preliminary report
}

Mohammed I. Al-Sebayel, MPH, FRCS, Yasser M. El-Sheikh, MD, FRCS, Falah H. Al-Mohanna, BSc, PhD,

Saleh I. Al Abbad, MBA, FRCS, Yaser H. Al Nemry, MBBS, SBS, Ahmed Al-Jammali, BSc, MME, Norah K. Al-Zeer, BSc, Yazeed M. Alsebayel, MBBS, Hamad M. Al-Bahli, MBBS, SBS.

\section{ABSTRACT}

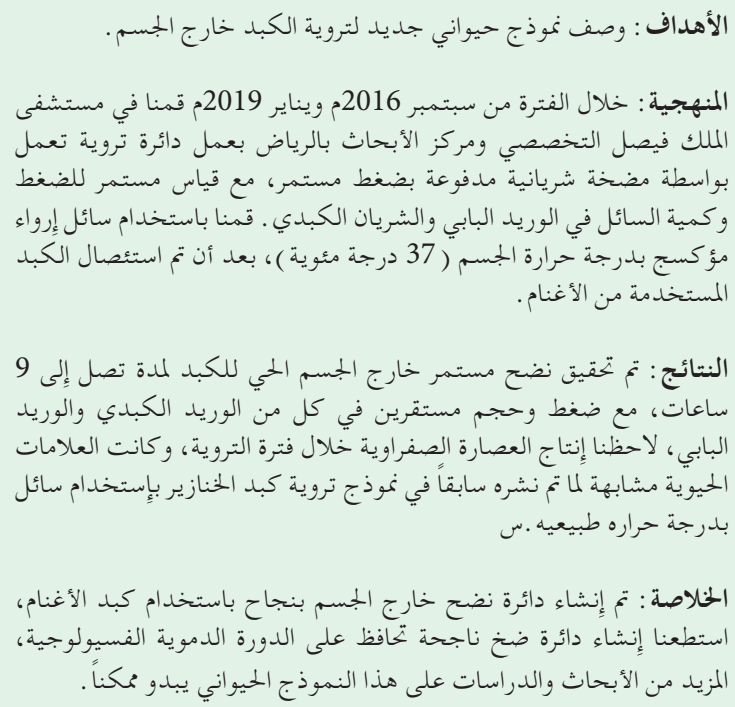

Objectives: To describe a novel animal model for ex-vivo liver perfusion.

Methods: This study was carried out at King Faisal Specialist Hospital and Research Center, Riyadh, Saudi Arabia, between September 2016 and January 2019. We assembled a perfusion circuit operated by a continuous pressure-driven arterial pump with continuous portal and arterial pressure and volume measurements. We used normothermic oxygenated perfusate. The livers used were retrieved from the sheep.

Results: Ex-vivo continuous perfusion of the liver was achieved for up to 9 hours with stable pressure and volume in both hepatic artery and portal vein. In 4 experiments the arterial pressure was kept in a range of $48-52 \mathrm{mmHg}$ with a mean of
$51.75 \pm 4.31$ resulting in arterial volume at steady state of $223.5 \pm 48.25 \mathrm{ml} /$ minute $(95 \%$ confidence level). At steady state the mean portal pressure was $16.25 \pm 1.45 \mathrm{mmHg}$ with a mean volume of $854 \pm 313.75 \mathrm{ml} /$ minute $(95 \%$ confidence level). Bile production was observed during the perfusion period. Hemodynamic parameters were similar to the physiological parameters observed in normothermic perfusion model of the porcine liver.

Conclusion: A normothermic oxygenated ex-vivo perfusion circuit was successfully constructed using the sheep liver. A sustainable functional circuit with physiological hemodynamic parameters was achieved. Further study on sheep model seems to be feasible.

Keywords: porcine liver, machine perfusion, organ preservation, hepatic flow, animal handling

Saudi Med J 2021; Vol. 42 (12): 1289-1295 doi: 10.15537/smj.2021.42.12.20210054

From the Department of Liver Transplantation \& HepatobiliaryPancreatic Surgery (Al-Sebayel, El-Sheikh, Al Abbad, Al Nemry, Al-Jammali, Al-Zeer, Alsebayel, Al-Babli); and from the Department of Comparative Medicine (Al-Mohanna), King Faisal Specialist Hospital \& Research Center, Riyadh, Kingdom of Saudi Arabia.

Received 5th July 2021. Accepted 18th October 2021.

Address correspondence and reprint request to: $D r$. Mohammed I. Al-Sebayel, Department of Liver Transplantation o Hepatobiliary-Pancreatic Surgery, King Faisal Specialist Hospital \& Research Center, Riyadh, Kingdom of Saudi Arabia. E-mail:msebayel@gmail.com ORCID ID: -https://orcid.org/0000-0003-4517-6344 
$\mathrm{O}$ rgan preservation has been an important aspect in the logistics of organ transplantation that remarkably affects the eventual outcome of organ transplantation. Classically, this has been carried out through cold storage of the organs in order to decrease their metabolic rate, until they are perfused in the recipient. ${ }^{1}$ Though this has been very successful, it neither allows for the extension of preservation time nor for judging the quality of organs. Another disadvantage of cold preservation is the fact that it does not allow the manipulation of the organ in order to improve its quality while being prepared for implantation. Moreover, due to the higher complication rate, static cold storage does not seem to provide adequate protection to the harvested organs and other preservation strategies might be required for their safe use in transplantation. With these goals in mind, organ preservation using ex-vivo perfusion has been performed successfully in kidney and lung preservation. ${ }^{2,3}$ However, clinical experience with ex-vivo liver preservation is limited..$^{4-7} \mathrm{On}$ the other hand, there is a lot of experimental work carried out in both small and large animal models. ${ }^{8-12}$ Of particular interest is the most recent advance in experimental liver machine perfusion, in which purification of the perfusate was assessed in porcine model. ${ }^{13}$ In this study, we describe our initial experience with ex-vivo perfusion of the liver using the sheep as a novel animal model which is readily available especially in countries where using a porcine model is not possible for religious or cultural reasons. We also describe the circuit setup and the hemodynamic variable during isolated liver perfusion.

Methods. The research project was carried out between September 2016 and January 2019 after obtaining the necessary ethical approval at King Faisal Specialist Hospital and Research Center, Riyadh, Saudi Arabia.

In general, outbred male weanling sheep $(30-40 \mathrm{~kg})$ of Naimi strain (Ovis aries, Awassi), were used. The sheep were obtained from local market and housed in accordance with the international regulations for the Care and Use of Laboratory Animals. ${ }^{14}$ The sheep were placed in temperature and light-controlled cages under

Disclosure. This study was funded by King Abdulaziz City for Science and Technology, Riyadh, Saudi Arabia. Project title: Rescue therapy of retrieved organs from deceased donors: liver ex-vivo machine perfusion (13-MED150320). a 12:12 h light: dark cycle and provided with food and water ad libitum. The sheep were given 2 weeks acclimation period. A thorough physical examination, including the assessment of temperature, cardiac function, pulmonary ventilation, and hydration status by assessing mucous membrane color, and pulse quality was performed. Blood samples from jugular vein were obtained for routine laboratory work-up, including complete blood count, and chemistry profile to determine the animal health status. Initially we started with the strain Barbary (Ammotragus lervia) in 3 cases. However, the anatomy of the hepatic artery was found unsuitable because of its size and variability.

The sheep were premedicated with xylazine (0.05-0.2 $\mathrm{mg} / \mathrm{kg} \mathrm{IM).} \mathrm{The} \mathrm{sheep} \mathrm{were} \mathrm{weighed} \mathrm{and} \mathrm{taken}$ to the operating table, still spontaneously breathing, 15 minutes (mins) after premedication. A 16-gauge $31 / 4$ inch percutaneous jugular catheter was placed and secured to allow for administration of induction agents, supplemental parenteral anesthetics and analgesics, and IV fluids. Propofol $4 \mathrm{mg} / \mathrm{kg}$ was injected through the IV route for induction. The sheep were then placed in sternal recumbency with a soft rope placed around each of the upper and lower jaw to facilitate opening the mouth and holding the head and neck elevated and extended. Using a laryngoscope, the larynx was visualized, and approximately $2 \mathrm{ml}$ of lignocaine $20 \%$ was dripped onto the larynx using a syringe with $51 / 4$ inch catheter without stylet. The endotracheal tube (ET) with an internal diameter of $8 \mathrm{~mm}$ was inserted, secured, and the cuff inflated. A large oral-gastric tube was inserted aiming to go as far as possible without undue force with the aim of proper positioning in the rumen of the multipartite stomach after laparotomy. At this point, the head could be lowered, and the sheep were positioned for surgery. The sheep were preoxygenated with $100 \%$ oxygen and was administered inhaled isoflurane $(2-5 \%$, titrated to effect) to deepen the sedation. The sheep were ventilated with volumecontrolled intermittent positive pressure ventilation to maintain the end-tidal $\mathrm{CO}_{2}$ between $35-40 \mathrm{mmHg}$ and $\mathrm{PaO} 2$ between 200-240 mmHg. A 16-gauge catheter was placed in the right carotid artery for continuous monitoring of the sheep's blood pressure. Anesthesia was maintained with isoflurane (1-2\% titrated to effect prior to skin incision. Fentanyl (100 mg followed by $50 \mathrm{mg} / \mathrm{h} \mathrm{IV}$ ) was administered for analgesia. Warm crystalloid solution $(0.9 \% \mathrm{NaCl}, 20-25 \mathrm{ml} / \mathrm{kg} / \mathrm{h})$ was administered during the procedure.

A midline incision was made, with a right transverse extension. The abdominal cavity was then explored. The oral-gastric tube was palpated and positioned in the rumen reservoir of the stomach which is the largest 
of the 4 stomach reservoirs. The abdominal viscera was retracted to the left, and the inferior vena cava (IVC), and aorta were exposed (Figure 1A). This was followed by mobilizing the infrarenal aorta that was encircled. We then exposed the supra-celiac aorta by incising the diaphragmatic crura. It was encircled with umbilical tape (Figure 1B). Attention was then paid to the hilum of the liver where the hepatic artery was identified and dissected as proximally as possible (Figure 1C).

The common bile duct was then dissected. We then cannulated and connected the aorta to a cold saline bag. The aorta and IVC were ligated at the iliac branching to exclude the lower limbs. The aorta was clamped at the supra-celiac part. The perfusate was then started, and the IVC was incised immediately to drain the circulation out. Saline perfusion was continued until the drainage started to clear. We then perfused using Histidine-Tryptophan-Ketoglutarat (Custodiol $^{\odot}$ HTK, Dr Franz Köhler Chemie GmbH, Germany) preservation solution. The liver was then procured. The aorta and IVC were dissected with ligation of the renal and superior mesenteric vessels. The structures of the hilum were then exposed. The portal and superior mesenteric veins were dissected carefully and ligated. The left gastric and the splenic arteries were ligated. The retrieval of the liver was completed with incising the diaphragm and IVC at the right atrium and finally the thoracic aorta. The average weight of livers was 876 grams.

The ex-vivo perfusion circuit, which was built in-house at the King Faisal Specialist Hospital and Research Center, Riyadh, Saudi Arabia, was the modification of the circuit used by the Toronto group. ${ }^{15}$ The components of the circuit include the following: biomedical pump (Bio-Pump ${ }^{\oplus}$ Centrifugal pump, Medtronic, Minneapolis, MN, USA); inflow tubing (portal and arterial); exit tubing (venous outflow); portal flow reservoir; heat exchange and oxygenator; and flow meters and monitor (System $\mathrm{M}^{\oplus}$, Spectrum Medical, USA).

We also designed a metallic reciprocal with the necessary inflow and outflow gadgets. A fully functioning circuit, which was tested several times with necessary modifications, was thus developed (Figure 2).

After the completion of the connections, the circuit was started by switching on the biomedical pump
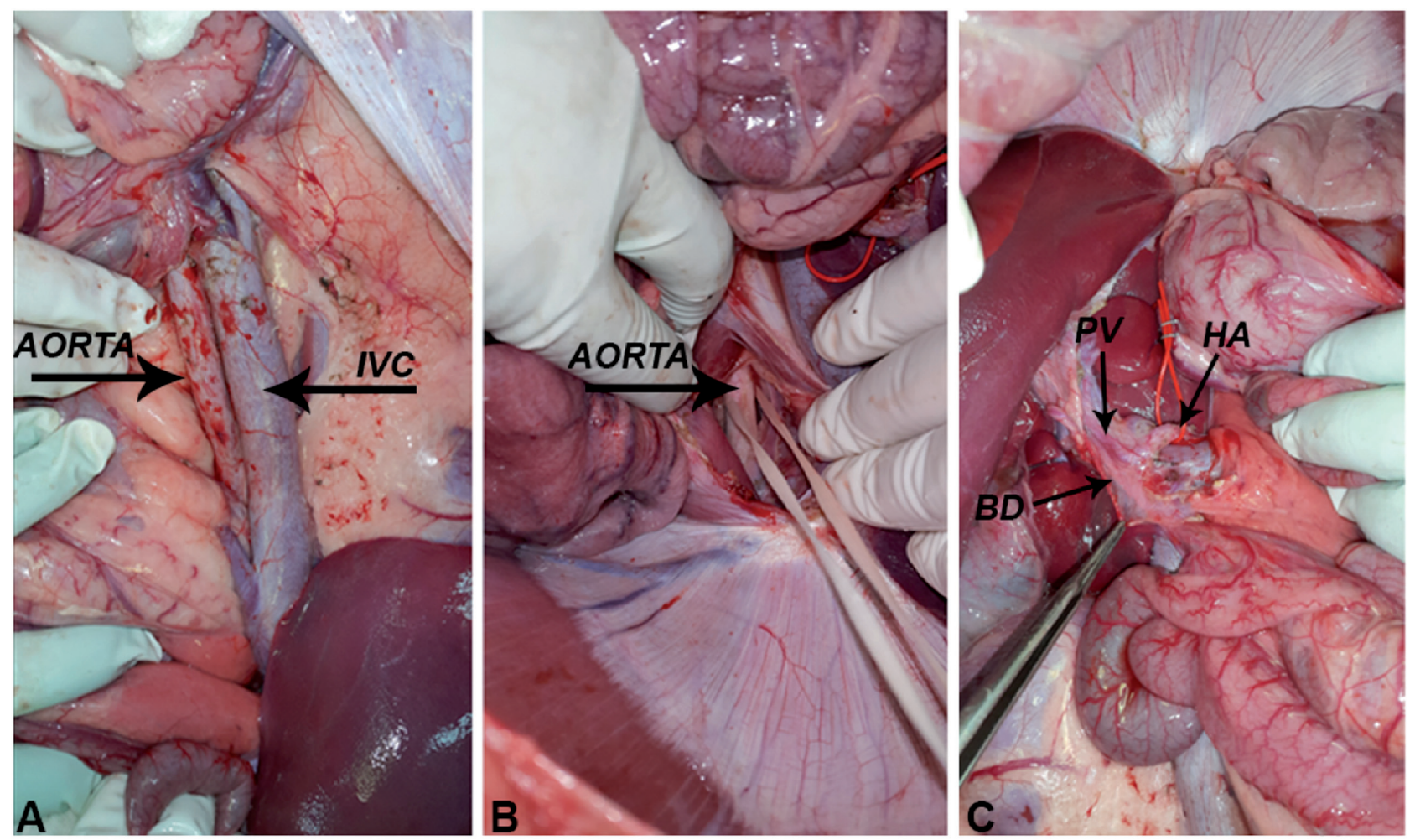

Figure 1 - Sheep liver harvesting. A) The aorta and inferior vena cava (IVC) exposed for cannulation. B) The aorta at the hiatus of the diaphragm exposed for clamping just prior to organ flushing in preparation for retrieval. C) Anatomy of the liver hilum in the sheep; the hepatic artery (HA) encircled with the portal vein (PV), and the common bile duct (BD) posteriorly and laterally. 

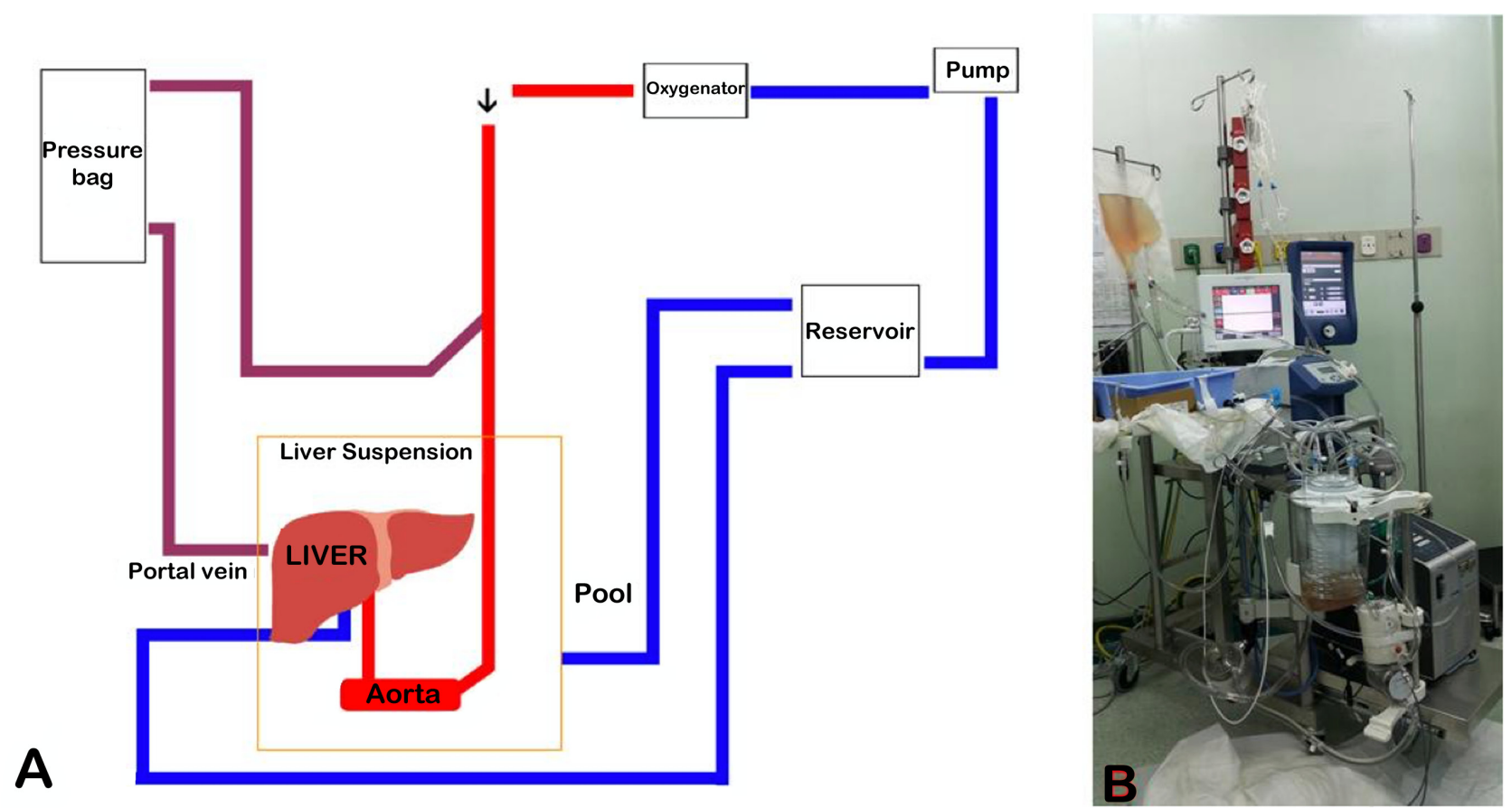

Figure 2 - Normothermic oxygenated machine perfusion circuit. A) A schematic representation. B) Components of the normothermic machine perfusion system.

with manual adjustment of the pressure in the hepatic artery aiming for a pressure of at least $50 \mathrm{mmHg}$ while observing the liver for overperfusion. The pressure in the portal vein was kept as low as possible by manually adjusting the height of the portal pressure bag (Figure 2A) while trying to keep the flow in the portal vein between $0.5-1.5 \mathrm{ml} / \mathrm{mins} / \mathrm{gram}$ of liver tissue and observing for overperfusion. The perfusates used were HTK (Custodiol' ${ }^{\circ}$, Dr Franz Köhler Chemie GmbH, Germany), Steen solution (STEEN Solution ${ }^{\mathrm{TM}}$ XVIVO, USA), and albumin-based fluid with packed red blood cells at hematocrit of $15 \%$. The fluid was normothermic and oxygenated with addition of heparin.

Results. We experimented on 10 livers after the successful retrieval. The mechanical characteristic of the circuit was the focus of the experiments trying to keep the flow, pressure, and volume as steady as possible. After several experiments, we managed to reach a steady state with continuous liver perfusion for up to 9 hours as shown in Figure 384. Flow and pressure were continuously monitored and projected into a real-life graphic image produced by System $\mathrm{M}^{\oplus}$ (Spectrum Medical, Fort Mill, SC, USA).

In the 4 experiments, the arterial pressure was kept in a range of $48-52 \mathrm{mmHg}$ with a mean of $51.75 \pm 4.31$ resulting in arterial volume at steady state

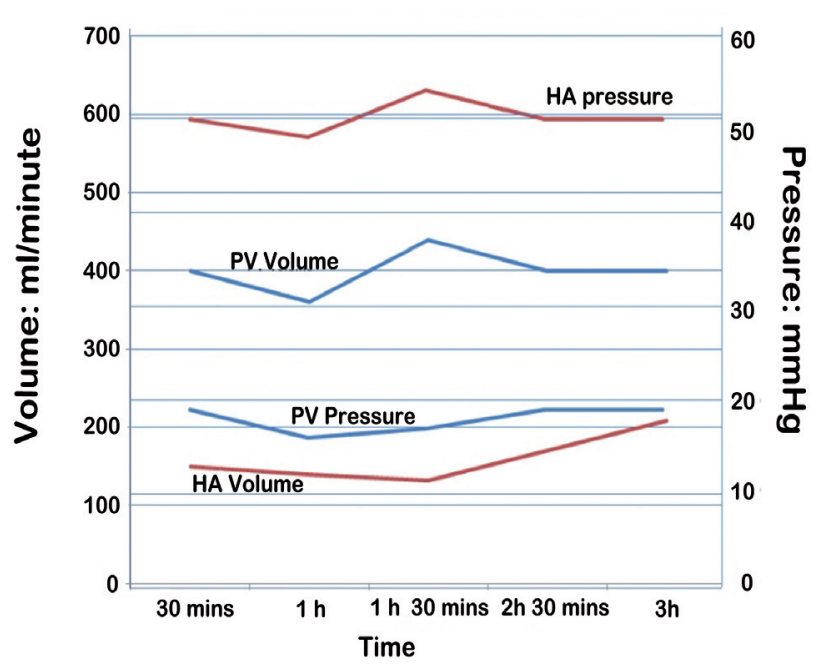

Figure 3 - Hemodynamics in the sheep liver showing a steady state over 3 hours with a portal pressure average of $16-19 \mathrm{mmHg}$ and volume up to $450 \mathrm{ml} / \mathrm{min}$. The hepatic artery (HA) pressure average is around $50 \mathrm{mmHg}$ with a volume of $120-200 \mathrm{ml} / \mathrm{min}$. PV: portal vein

of $223.5 \pm 48.25 \mathrm{ml} / \mathrm{mins}$ at $95 \%$ confidence level. The portal pressure was kept below $20 \mathrm{mmHg}$ by adjusting the height of the portal bag. At steady state the resulting mean portal pressure was $16.25 \pm 1.45 \mathrm{mmHg}$ with a mean volume of $854 \pm 313.75 \mathrm{ml} / \mathrm{mins}$ at $95 \%$ 


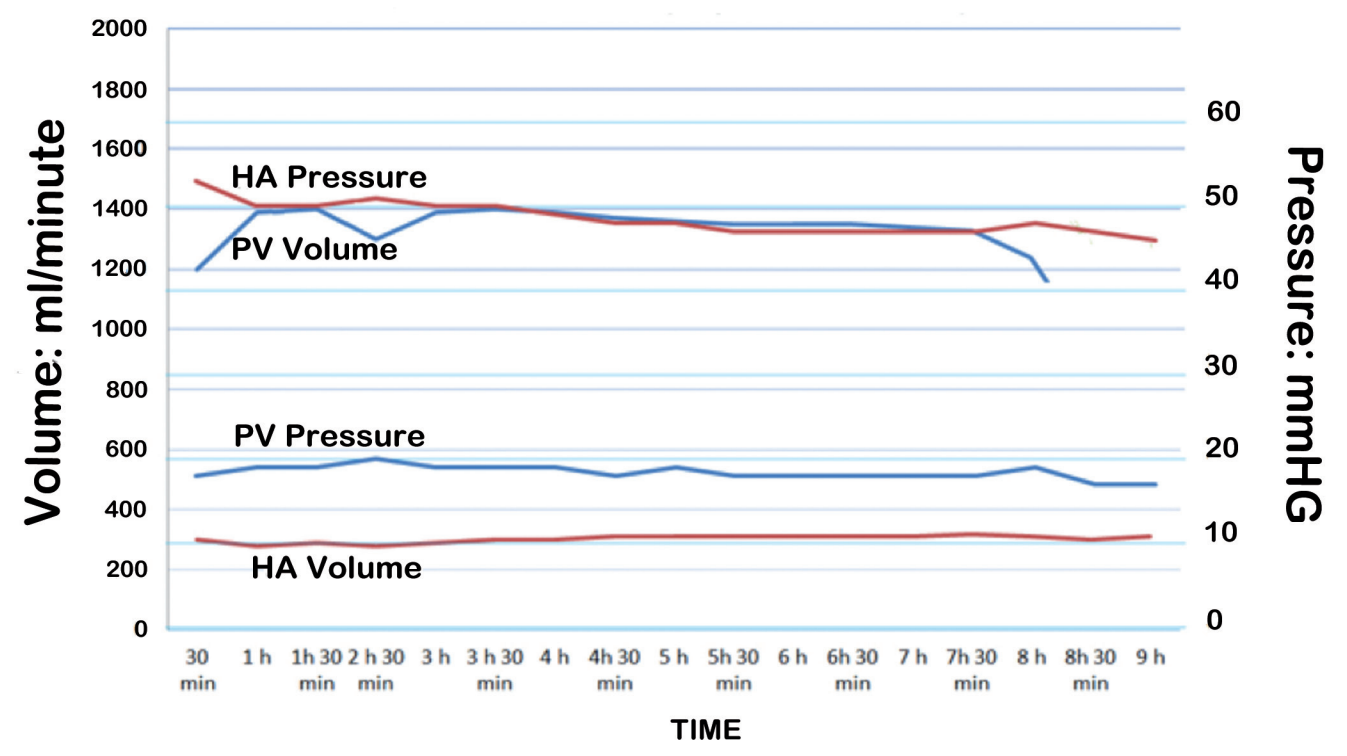

Figure 4 - Hemodynamics in the sheep liver showing a steady state over 9 hours with a portal pressure average of 17-20 $\mathrm{mmHg}$ and volume up to $1400 \mathrm{ml} / \mathrm{min}$. The hepatic artery (HA) pressure average is around $50 \mathrm{mmHg}$ with a volume of $300 \mathrm{ml} / \mathrm{min}$. PV: portal vein
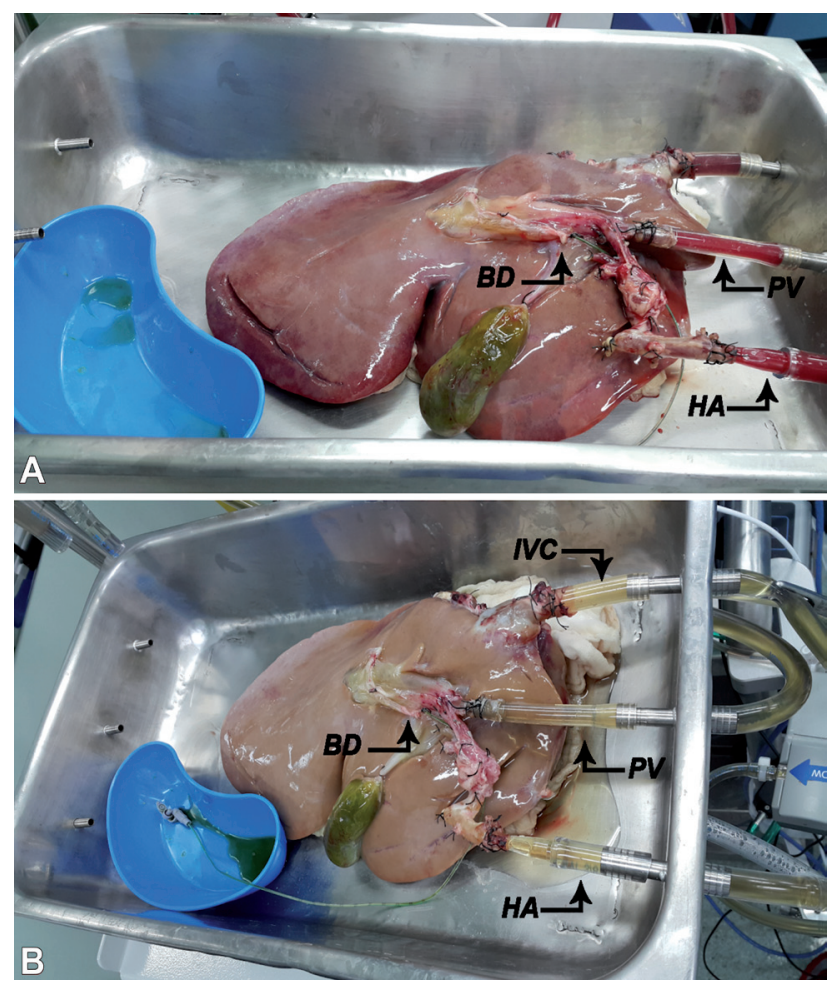

Figure $\mathbf{5}$ - Sheep liver with a cannulated hepatic artery (HA), portal vein (PV), and inferior vena cava (IVC). A) Perfused with normothermic oxygenated albumin-based fluid with packed red blood cells. B) Steen solution with resulting bile duct (BD) production. confidence level. The perfused liver produced bile as shown in Figure 5.

Discussion. Ideal settings for ex-vivo liver perfusion should consider the optimization of fluid dynamics, perfusion solution, temperature, and oxygenation. Oxygenation and temperature are relatively easy to control compared to the hemodynamics. The hemodynamics of liver circulation is complicated as it is the only organ in the body that receives blood from 2 sources (namely, the portal vein, and hepatic artery). The reciprocal contribution of volume and pressure in these 2 sources seems to be dynamic in response to different metabolic needs. The use of mechanical device to sustain physiological flow and pressure in ex-vivo circuit is very challenging since they are intimately interrelated hemodynamic parameters. Attentive regulation of these parameters is very crucial to have successful ex-vivo perfusion. High pressure may lead to shear stress that could be damaging to the sinusoidal endothelium. On the other hand, low pressure may cause sinusoidal collapse that could result in an heterogenous perfusion. The aim of the pressure-controlled perfusion is to approach near physiological pressures with portal pressure ranging between $5-15 \mathrm{mmHg}$ and an arterial pressure of 60-130 mmHg. Isolated porcine liver perfusion has been studied by several groups with variation in the hemodynamic paramours and difference in the way the 
Table 1 - Studies on isolated porcine liver normothermic perfusion utilizing arterial pressure circuit control. ${ }^{8,9}$

\begin{tabular}{|c|c|c|c|}
\hline Author & PV & HA & $\begin{array}{c}\text { Perfusion } \\
\text { period }\end{array}$ \\
\hline Butler, 2002 & $\begin{array}{l}7.22 \mathrm{mmHg} \\
1.75 \mathrm{~L} / \mathrm{min}\end{array}$ & $\begin{array}{l}90.3 \mathrm{mmHg} \\
240 \mathrm{ml} / \mathrm{min}\end{array}$ & $72 \mathrm{~h}$ \\
\hline Schön, 2001 & $\begin{array}{c}11 \mathrm{mmHg} \\
250 \mathrm{ml} / \mathrm{min}\end{array}$ & $\begin{array}{l}100 \mathrm{mmHg} \\
150 \mathrm{ml} / \mathrm{min}\end{array}$ & $4 \mathrm{~h}$ \\
\hline St Peter, 2003 & $\begin{array}{c}8 \mathrm{mmHg} \\
0.42 \mathrm{~L} / \mathrm{min}\end{array}$ & $\begin{array}{c}60-120 \mathrm{mmHg} \\
0.18 \mathrm{~L} / \mathrm{min}\end{array}$ & $3 \mathrm{~h}$ \\
\hline Jakob, 1990 & $\begin{array}{l}5-15 \mathrm{mmHg} \\
0.75 \mathrm{~L} / \mathrm{min}\end{array}$ & $\begin{array}{c}70-105 \mathrm{mmHg} \\
0.25 \mathrm{~L} / \mathrm{min}\end{array}$ & $24 \mathrm{~h}$ \\
\hline Ghonem, 2011 & $\begin{array}{c}18 \mathrm{mmHg} \\
350-475 \mathrm{ml} / \mathrm{min}\end{array}$ & $\begin{array}{l}100-130 \mathrm{mmHg} \\
150-220 \mathrm{ml} / \mathrm{min}\end{array}$ & $3.5 \mathrm{~h}$ \\
\hline Echeverri, 2018 & $\begin{array}{c}2-4 \mathrm{mmHg} \\
900-1200 \mathrm{ml} / \mathrm{min}\end{array}$ & $\begin{array}{c}60 \mathrm{mmHg} \\
400 \mathrm{ml} / \mathrm{min}\end{array}$ & \\
\hline Boehnert, 2013 & $\begin{array}{c}10 \mathrm{~cm} \mathrm{H} 2 \mathrm{O} \\
950 \pm 110 \mathrm{ml} / \mathrm{min}\end{array}$ & $\begin{array}{c}60 \mathrm{mmHg} \\
365 \pm 85 \mathrm{ml} / \mathrm{min}\end{array}$ & $12 \mathrm{~h}$ \\
\hline Banan, 2015 & $\begin{array}{c}12 \pm 4 \mathrm{mmHg} \\
1.2 \pm 0.2 \mathrm{~L} / \mathrm{min}\end{array}$ & $\begin{array}{l}85 \pm 10 \mathrm{mmHg} \\
0.5 \pm 0.1 \mathrm{~L} / \mathrm{min}\end{array}$ & $2 \mathrm{~h}$ \\
\hline He X, 2018 & $\begin{array}{c}8-10 \mathrm{mmHg} \\
310-590 \mathrm{ml} / \mathrm{min}\end{array}$ & $\begin{array}{c}80-100 \mathrm{mmHg} \\
110-240 \mathrm{ml} / \mathrm{min}\end{array}$ & \\
\hline
\end{tabular}

PV: portal vein, HA: hepatic artery, h: hours, min: minute, L: liter, ml: milliliter, $\mathrm{mmHg}$ : millimeter mercuryn h: hours

circuit is controlled. ${ }^{8,9}$ Table 1 lists some of the studies showing pressure and volume of the portal vein, and hepatic artery during isolated porcine perfusion. As can be seen, there is a wide variation in these values with hepatic artery pressure ranging between $59-130 \mathrm{mmHg}$ and volume of $150-600 \mathrm{ml} / \mathrm{min}$. The portal vein pressure varied between $5-18 \mathrm{mmHg}$ with volume ranging between $250-1750 \mathrm{ml} / \mathrm{min}$.

Using the sheep liver, we were able to sustain the circuit for more than 8 hours with a close range of volume, flow, and pressure in hepatic artery, portal vein, and hepatic vein. This needed a close monitoring of these parameters in order to prevent over perfusion and organ swelling, which is expected to have a deleterious effect on the organ. Our values are within the range of those obtained in an isolated porcine model.

Though the model is well established in pigs, we were able to apply it on sheep livers. in which the sheep liver was used. Of particular importance is the technical difficulties in dealing with the large multipartite stomach. Oral gastric tube, though essential had limited efficacy in deflating the stomach which makes surgical exposure challenging. This report concentrated on the mechanical characteristics of ex-vivo perfusion without looking at the biochemical characteristics. The outcome we have observed is very encouraging to proceed with further experimental work.
We demonstrated the potential of using sheep model to study isolated normothermic perfusion. This is especially important in countries where porcine model cannot be used for cultural and religious reasons.

Study limitations. The number of experiments executed were limited (4 successful experiments). There was a wide variation in the dynamics of the 4 experiments. However, we eventually managed to achieve stable flow and pressure dynamics which is comparable to those in the well-established porcine model. The other limitation of our study is the lack of biochemical measurements. The only functional parameter obtained was observing bile excretion. This work may open the door for using this novel animal model to explore isolated liver perfusion in future research.

In conclusion, we managed to build an ex-vivo perfusion circuit, in which we used the liver from a sheep model. We sustained 9 hours of continuous perfusion with relatively stable hemodynamics. This model is encouraging for further experimental studies on ex-vivo liver perfusion.

Acknowledgment. The authors gratefully acknowledge the staff of the Comparative Medicine at King Faisal Specialist Hospital and Research Center, Riyadh, Saudi Arabia, for their support throughout the project. We would also like to thank Mrs. Carla Mercado for the expert secretarial help. The authors would also like to thank Editage (ww.editage.com) for the English language editing.

\section{References}

1. Southard JH, Belzer FO. Organ preservation. Annu Rev Med 1995; 46: 235-247.

2. Gao X, Liu w, Liu M, Mingyao L. Ex Vivo Lung Perfusion: scientific research and clinical application. Prac J Organ Transplant 2017; 5: 177-187.

3. Moers C, Smits JM, Maathuis MH, Treckmann J, van Gelder F, Napieralski BP, et al. Machine perfusion or cold storage in deceased-donor kidney transplantation. N Engl J Med 2009; 360: 7-19.

4. Perera T, Mergental H, Stephenson B, Roll GR, Cilliers $\mathrm{H}$, Liang $\mathrm{R}$, et al. First human liver transplantation using a marginal allograft resuscitated by normothermic machine perfusion. Liver Transpl 2016; 22: 120-124.

5. Nasralla D, Coussios CC, Mergental H, Akhtar MZ, Butler $\mathrm{AJ}$, Ceresa CDL, et al. A randomized trial of normothermic preservation in liver transplantation. Nature 2018; 557: 50-56.

6. Laing RW, Mergental H, Yap C, Kirkham A, Whilku M, Barton $\mathrm{D}$, et al. Viability testing and transplantation of marginal livers (VITTAL) using normothermic machine perfusion: study protocol for an open-label, non-randomised, prospective, single-arm trial. BMJ Open 2017; 7: e017733.

7. Laing RW, Mergental H, Mirza DF. Normothermic ex-situ liver preservation: the new gold standard. Curr Opin Organ Transplant 2017; 22: 274-280. 
8. Maione F, Gilbo N, Lazzaro S, Friend P, Camussi G, Romagnoli $\mathrm{R}$, et al. Porcine isolated liver perfusion for the study of ischemia reperfusion injury: a systematic review. Transplantation 2018; 102: 1039-1049.

9. Eshmuminov D, Leoni F, Schneider MA, Becker D, Muller $\mathrm{X}$, Onder C, et al. Perfusion settings and additives in liver normothermic machine perfusion with red blood cells as oxygen carrier. A systematic review of human and porcine perfusion protocols. Transpl Int 2018.

10. Echeverri J, Goldaracena N, Kaths JM, Linares I, Roizales R, Kollmann D, et al. Comparison of BQ123, epoprostenol, and verapamil as vasodilators during normothermic ex vivo liver machine perfusion. Transplantation 2018; 102: 601-608.

11. Goldaracena N, Echeverri J, Spetzler VN, Kaths JM, Barbas AS, Louis KS, et al. Anti-inflammatory signaling during ex vivo liver perfusion improves the preservation of pig liver grafts before transplantation. Liver Transpl 2016; 22: 1573-1583.
12. He X, Ji F, Zhang Z, Tang Y, Yang L, Huang S, et al. Combined liver-kidney perfusion enhances protective effects of normothermic perfusion on liver grafts from donation after cardiac death. Liver Transpl 2018; 24: 67-79.

13. Obara H, Morito N, Matsuno N, Yoshikawa R, Nakajo T, Gochi $\mathrm{M}$, et al. Initial perfusate purification during subnormothermic machine perfusion for porcine liver donated after cardiac death. J Artif Organs 2020; 23: 62-69.

14. National Research Council. Guide for the Care and Use of Laboratory Animals: Eighth Edition. Washington, DC: The National Academies Press; 2011.

15. Boehnert MU, Yeung JC, Bazerbachi F, Knaak JM, Selzner N, McGilvray ID, et al. Normothermic acellular ex vivo liver perfusion reduces liver and bile duct injury of pig livers retrieved after cardiac death. Am J Transplant 2013; 13: 1441-1449. 